\title{
AVERROES, Y LA CRÍTICA DE AVICENA
}

\author{
Josep Puig Montada \\ Universidad Complutense de Madrid
}

\section{RESUMEN}

En su obra refutando a los filósofos, el teólogo Algacel (m. 1111) ataca sus doctrinas acerca de la causalidad divina con argumentos que quieren demostrar su incoherencia. Destaca la crítica a la distinción que hace Avicena (m. 1037) entre ser necesario por sí mismo, y ser posible por sí mismo, pero necesario por causa de otro, distinción en que se basa su doctrina de la causalidad. Cuando Averroes (m. 1198) refuta, a su vez, la obra de Algacel, señala que las doctrinas que este atacaba no eran propias de Aristóteles, sino de Avicena, y a menudo se aparta de este.

Palabras clave: Avicena, Algacel, Averroes, Causalidad divina.

\begin{abstract}
In his refutation of the philosophers, the Muslim theologian al-Ghazzali (d. 1111) argues for the incoherency of their doctrines on divine causality. He focuses his criticism on Avicenna's (d. 1037) distinction between being necessary per se, and being possible per se, although necessary because of another. When Averroes (d. 1198), on his turn, rebates al-Ghazzâl's work, he points out that the doctrines ascribed to the philosophers, are those of Avicenna, and not of Aristotle and often distances himself from the later.
\end{abstract}

Key words: Avicena, Algacel, Averroes, Divine causality.

El Tahâfut at-Tahâfut es mucho más que la refutación del Tahâfut al-Falâsifa de Algacel, es también una rectificación por Averroes de las opiniones de los filósofos que Algacel dice transmitir para luego rebatir. Estos filósofos son sobre todo Avicena: Lo sabemos desde hace años, cuando Manuel Alonso en su introducción a la traducción de las Intenciones de los filósofos de Algacel señaló que esta obra era un plagio del Libro de la ciencia de Avicena ${ }^{1}$ y ahora, para otros textos, Jules Janissens ha hecho descubrimientos comparables ${ }^{2}$.

En lo que concierne, en general, al Tahâfut al-Falâsifa, Jules Janssens ha mostrado que la enciclopedia filosófica denominada el Libro de la curación de Avicena y muy en particular

1 Maqâsid al-falâsifa o Intenciones de los filósofos, Barcelona, 1962, «Fuente principal», pp. XLV-LI. Una cuestión por resolver es si la obra representa el pensamiento de Algacel en una fase de su vida, o solamente es la exposición del pensamiento aviceniano con el objeto de rebatirlo en su Tahâfut al-Falâsifa, la Destrucción de los filósofos.

2 «Le $M a$ ârij al-quds fî madârij ma 'rifat an-nafs: un élément-clé pour le dossier Ghazzâlî-Ibn Sînâ?», en Archives d'histoire doctrinale et littéraire du Moyen Age, 60 (1993), pp. 27-55.

«Le Mi 'yăr al-'ilm fî fann al-mantiq d'al-Ghazzâlî: sources avicenniennes et farabiennes», Archives d'histoire doctrinale et littéraire du Moyen Âge 69 (2002), pp. 39-66. 
el volumen de la Metafísica, aunque también el del Alma, inspiran la formulación de Algacel ${ }^{3}$. Sin embargo, estas fuentes no están presentes de manera visible en Algacel e incluso, a veces, resulta difícil identificarlas.

En el presente trabajo examinaré las tesis atribuidas a Avicena en la cuestión III del Tahâfut al-Tahâfut $t^{4}$ en su caso la crítica de Averroes, de modo que prestaré menos atención a su refutación de Algacel, objetivo fundamental de la obra, y de esa cuestión. Mi primer objetivo es saber si todas las tesis atribuidas a Avicena son realmente suyas porque no tenemos ninguna prueba de que Averroes dispusiera de las obras de este. En alguna ocasión ${ }^{5}$, hace referencia a la principal obra de Avicena, El libro de la curación ${ }^{6}$ pero parece, en general, que está reconstruyendo su pensamiento a partir de lo que dice Algacel. En caso de que las tesis sean avicenianas, averiguaremos si Averroes lo está rebatiendo, tal como nos dice a menudo, o si lo acepta, algo que no suele decir.

En el tercer libro de Tahâfut al-Falâsifa, es decir, el Desplome de los filósofos ${ }^{7}$, Algacel denuncia la incapacidad de los filósofos para demostrar que Dios es la causa eficiente, o el agente, del mundo. Está de acuerdo con Avicena en que el agente propiamente dicho da la existencia al efecto, pero añade otras condiciones:

El agente no es denominado agente ni artífice por el simple hecho de ser una causa sino por ser una causa en un aspecto particular, que es el aspecto de la voluntad y de la elección (TF $57[4])$.

Recordemos que los filósofos musulmanes, siguiendo a Plotino, optaron por una génesis del universo mediante emanación: Dios es Unidad y de ella emana la multiplicidad de lo creado. Frente a esto, Algacel y los teólogos defienden a un Dios con voluntad como única posibilidad de salavaguardar la unidad divina y su acción eficiente.

Algacel dispone su ataque contra la teoría emanacionista de los filósofos en tres frentes: el agente, el acto, y la relación entre agente y su acto.

\section{PRIMER ASPECTO (AGENTE)}

Según vosotros [filósofos] el mundo procede de Dios como el efecto procede de la causa, con una consecuencia necesaria, no podemos imaginarnos que Dios lo impida, como la sombra es consecuencia necesaria de la persona que está a la luz del sol» (TF 57 [4]).

3 «Al-Ghazzâlîs Tahâfut: Is it really a Rejection of Ibn Sînâ’s Philosophy?» en Journal of Islamic Studies 12: 1 (2001), pp. 1-17.

«AI-Ghazâlî and his Use of Avicennian Texts», in Problems in Arabic Philosophy, pendiente de publicación.

4 Edición de Maurice Bouyges, Beirut, 1930. Traducción inglesa de S. van den Bergh, The Incoherence of the Incoherence, 2 vols. Londres, 1954. Abreviamos TT.

5 En el comentario medio de la Metafisica - texto pendiente de publicación por M. Zonta- conservado, entre otros manuscritos, en el de Roma B.R. Casanatense, Hebr. 3083, nos habla del libro «llamado al-Shifâh» (folio 141 recto, 11. 18-20), según advirtió H.A. Davidson, Proofs for Eternity, Creation and the Existence of God in Medieval Islamic and Jewish Philosophy (Oxford University Press, 1987), nota en p. 334. Por el contexto, parece que Averroes no disponía de la obra de Avicena y hablaba de oídas.

6 Sabemos que Abû Bakr Ibn Țufail (m. 1185), amigo de Averroes, disponía del Kitâb ash-Shifà', según indica al comienzo de su Risâlat Hayy Ibn Yaqzân, ed. Léon Gauthier, 2 ed. (Beirut 1936, con trad. francesa), pp. 1415. Traducción de A. González Palencia, El filosofo autodidacto (1934. Madrid, 1999), pp. 36-38.

7 Edición de Maurice Bouyges, Beirut 1927. Reeditado, sin el aparato crítico, con traducción inglesa por Michael E. Marmura, Provo, Utah, 1997. Las citas se hacen por la edición de Marmura, abreviando TF, y entre paréntesis, los párrafos en su numeración. 
Avicena puede suscribir esta afirmación, pues en el Shifâ' la encontramos expresada de una manera parecida ${ }^{8}$. Algacel la refuta, pues considera que el único agente es el que quiere y escoge, de modo que la piedra o el fuego no pueden ser causas eficientes. A pesar de ello, presenta la respuesta de los filósofos a su objeción: causa es un género, que se divide en causa por naturaleza o por la voluntad. Esta distinción es admitida por todos los filósofos, no sólo por Avicena ${ }^{9}$, por cuanto admiten la causalidad en la naturaleza, que justifica las leyes que la ciencia descubre.

Sin embargo, Algacel no acepta esta división. El agente por naturaleza es una metáfora del verdadero agente, el voluntario y no es lícito denominar agente a cualquier causa (TF 58 [8]). A continuación pone en boca de los fílósofos una respuesta, que sostiene que el término 'acto' $\left(\mathrm{fa}^{\prime} \mathrm{l}\right.$ ) se aplica correctamente tanto a los actos voluntarios como naturales, pero esto es algo que Algacel no puede admitir porque supone que «si Dios no quiere ni escoge no es artífice ni agente más que metafóricamente» (TF 60 [13]). Viene luego la presentación por Algacel de la tesis de los filósofos: «Dios es la causa de todos los demás seres y el mundo subsiste gracias a Él» (TF 60 [15]), esto es ser el agente según ellos.

Este es un punto discutible, pues no encontramos en Avicena la afirmación exacta ${ }^{10}$ y es probable que Averroes tenga razón cuando contesta que todos los filósofos rechazarían esta afirmación que llevaría a tener a Dios por un principio comparable a la forma - unida a la materia- en el compuesto sustancial (TT 161).

Algacel tiene que insistir en su argumento de que la creación del mundo en la versión de los filósofos no es «acto» porque no es un acto voluntario y Averroes tiene que contestarle que tergiversa las palabras de los filósofos (TT 161).

\section{SEGUNDO ASPECTO (ACTO)}

La creación del mundo no puede ser un acto de Dios, si nos atenemos a la doctrina de los filósofos. Según Algacel, «El significado de 'acto' es hacer pasar algo de la inexistencia a la existencia mediante su producción temporal» (ihdâth, TF 61), pero si el mundo es eterno es inconcebible este paso, al no haber una producción temporal.

Averroes considera, todo lo contrario, que una creación eterna es una producción más genuina, más fuerte, y que merece un agente con más razón (TT 162). Sin embargo Algacel dice conocer la contestación de los filósofos: El agente no tiene ninguna influencia en la inexistencia, y la relación del mundo con el Agente es la existencia. Algacel pone en boca de los filósofos lo siguiente:

Por esto hemos establecido que el mundo es el acto de Dios desde la eternidad y para siempre, y que no hay momento alguno en el que Dios no sea su agente puesto que el vínculo con el Agente es la existencia (TF 62 [23]).

8 Ibn Sînâ, Kitâb ash-Shifâ’', al-llâhtŷât, ed. Sa'îd Zâyed y Georges C. Anawati, El Cairo, 1960. Reprint de Qom, 1404/1983-4. Citado en adelante como Ilâhîyât, aquí p. 266. Traducción francesa de G.C. Anawati, La métaphysique du Shifấ, vol. 2 (París, 1978), p. 21.

Así mismo, Kitâb al-ishârât wa-t-tanbîhât. Ed. Jacob Forget, Le livre des théorèmes et des avertissements, vol. 1 (Leiden, 1892), pp. 152-153. En adelante citado como Ishârât. Traducción francesa de A-M. Goichon, Livre des directives et remarques (Beirut-París; 1951), p. 384-385.

Recordemos que este es el argumento de la segunda cuestión del Tahâfut, pues para Algacel, Dios existía, pero no el mundo. En cuanto a la noción de «consecuencia necesaria», puede consultarse lo que A-M. Goichon escribió sobre lâzim en La distinction de l'essence et de l'existence d'après lbn Sînâ (París, 1937), p. 218.

9 La distinción aparece, por ejemplo, en Ishârât, p. 152.

10 Ver Ilâhîyât, Libro VIII, c.4, pp. 344-362, sobre los atributos del Dios. 
Algacel llamará la atención sobre la absurdidad de hacer pasar a la existencia algo que eternamente existe (TF 63), pero Averroes no acepta que este sea el punto de vista de todos los filósofos, sino solamente de Avicena. En efecto, en Avicena encontramos que la existencia del efecto, y no la inexistencia, dependen del agente. Lo leemos en las Intenciones de los filósofos de Algacel, un plagio - como se ha dicho- del Libro de la ciencia de Avicena:

El agente no influye en que el ser exista precisamente después de no existir porque no es posible que tal existencia se prođuzca sino después de no existir el ser. Dase por lo mismo después de no existir el ser por sí mismo... El que exista después de no existir no es porque alguien positivamente ejecute el no existir, antes bien el influjo del agente se da tan sólo respecto de su existencia ${ }^{11}$.

Similares afirmaciones aparecen en otras obras, como el Libro de la salvación ${ }^{12}$ o en la gran enciclopedia, Shifâ', donde insiste en que el no ser carece de causa ${ }^{13}$.

Aquí aparece la primera crítica de Averroes a Avicena, interrumpiendo su exposición en nombre de los filósofos. Entiende que su argumento es defectuoso porque ignora la función de la potencialidad en todo proceso. Según él, que se identifica con los aristotélicos, todo proceso de cambio exige una existencia deficiente, o dicho al revés, una inexistencia relativa, la existencia en potencia. Averroes admite dos variantes en los procesos de cambio: en una el objeto generado está libre de inexistencia (existencia en potencia), y en otra, no. El producto del artesano existe libre de inexistencia, y sobrevive a la producción, pero el movimiento nunca existe libre de su agente, el movimiento es un acto imperfecto, contaminado de inexistencia. Averroes distingue tres niveles: el mundo supralunar que necesita continuamente de su creador, en cuanto es motor, pues es su verdadero agente, el mundo sublunar, que lo necesita en menor grado, y los productos del arte, todavía menos ligados a su agente (TT 164-165).

Algacel continúa presentando la posición de los avicenianos: Causa, efecto y causación son simultáneos, y no hay vínculo causal más que para lo existente, y por esta razón, en el conjunto del universo:

La inexistencia no está relacionada con él [agente] de ningún modo, y el universo en cuanto no existe no necesita de ningún agente, de modo que está relacionado con él solamente en cuanto existe (TF 61 [20]).

Esta es una tesis de Avicena, y la encontramos en el Shifâ', por ejemplo. Si el agente existe eternamente, existe su efecto eternamente, y esta causalidad es la más valiosa porque impide cualquier inexistencia de la cosa ${ }^{14}$. De hecho, la simultaneidad entre causa y efecto es un corolario de la tesis emanacionista del universo, de origen neoplatónico. ¿Cómo va a reaccionar Averroes?

Primero, reiterando su tesis de que el efecto puede existir independientemente de la causa si no adolece de inexistencia, y por esto la casa subsiste después de su construcción. Luego introduce una distinción: si es esencial o no para una cosa el hecho de ser causada, que esta sea su sustancia (TT 166). Averroes no está de acuerdo en que la sustancia del mundo sublunar con-

11 Maqâșid, trad. M. Alonso, p. 132.

12 Kitấb an-najât, vol. 2, (Cairo, 1913), p. 347-8, contra los mutakallimíes. Ed. M. Fakhry, (Beirut, 1985), p. 249-250, en adelante citamos por la edición de Fakhry. Avicena no está de acuerdo con ellos en dar entidad a los no-existentes ( $m a$ 'dûmât).

Traducción latina de Nematallah Carame (1593), Metaphysices compendium, Roma 1926.

13 En concreto, Ilâhîyât, Libro VI, c. 1, pp. 259-261

14 Ilâhîyât, Libro VI, c. 2, p. 266. Ishârât, p. 113. También en Ta'līqāt (Anotaciones), ed. 'A. Badawî (Cairo, 1973), p. 176, rebate el ejemplo de la casa que subsiste independientemente del albañil y señala que el albañil es causa «por accidente» y que las verdaderas causas son otras, los elementos que mantienen la casa en pie. 
sista en ser causada, pero concede que Avicena puede tener razón, en cuanto a las esferas celestes, seres inmateriales cuya esencia es pensar en la Primera Causa y esto es causa de su existencia.

Es curiosa la coincidencia parcial entre Algacel y Averroes, pues el primero también se apoya en que el acto no está unido al agente una vez se ha generado, y que solamente está unido a él «mientras llega a ser» (TF 63 [25]). Ahora bien, Averroes constata que el mundo está continuamente en movimiento, y por tanto continuamente necesitado de su agente Aún más, la forma del mundo es relativa, está en relación con su aprehensión del la Causa Primera (TT 167168).

Por su parte, Algacel insiste en su defensa de que la creación exige que la inexistencia preceda a la existencia y en excluir una creación eterna pues no sería un verdadero acto (TF 63). Sin embargo, Algacel reconoce la evidencia de movimientos simultáneos, como el del agua movida por el dedo, y de suponerse que el dedo se mueva eternamente, el movimiento del agua también lo sería (TF 63-64). Por ello, no niega que haya acciones simultáneas con el agente, pero la acción tiene que ser producida temporalmente:

No excluimos la posibilidad de que el agente y el actó sean simultáneos siempre que el acto sea producido temporalmente (hâdith), tal como ocurre con el movimiento del agua, pues tiene lugar después de su inexistencia (TF 64 [29]).

Algacel vuelve a recordarnos sus dos tesis: el único acto es el voluntario, y la acción tiene que ser precedida de la inexistencia en el tiempo. Por otra parte, Averroes sostiene que la creación es una acción eterna que hace pasar el mundo de la inexistencia a la existencia de manera continua. Los detalles de esta acción nos lo da también:

El fundamento, para los aristotélicos, es que la existencia de los cuerpos celestes subsiste a causa del movimiento y que Aquel que les da el movimiento es de verdad la causa eficiente del movimiento y puesto que la existencia de los cuerpos celestes solamente se hace realidad a través de su movimiento, Aquel que les da el movimiento es el agente de los cuerpos celestes (TT 172).

Otro detalle de esta acción es que en el caso de un compuesto, la causa que los une es el agente que da la existencia, y está claro que Dios mantiene unido el universo. Un nuevo instrumento aparece en manos de Averroes: wahdânîy $a,{ }^{15}$ un derivado de wahda, 'unidad', y que es su concepto transcendental, y que volverá a utilizar.

En suma, no podemos hablar de crítica de Averroes a Algacel, ni de éste a los filósofos porque, en realidad, nos encontramos ante modelos contrapuestos. En todo caso, la crítica tiene sentido entre Averroes y Avicena, en cuanto el primero se distancia de la filosofía emanacionista del segundo.

15 TT, p. 172: 7. El término aparece en Avicena, y N. Carame lo tradujo por unicitas, Kitâb an-Najât (p. 80), donde en una nota a pie de página, se refiere a los conceptos escolásticos de atributo 'predicamental' y 'trascendental' para señalar que además hay otro sentido de 'unidad' el cual se aplica solamente a Dios y consiste en esta unitate speciali et exclusiva quae dicitur unicitas. No me parece, sin embargo, que la distinción se pueda aplicar a Averroes que lo utiliza en el sentido escolástico de 'trascendental', o asimilable, como unidad emanada del Uno en los demás seres y de la que participan. Cf. Ishârât, p. 461 . 


\section{TERCER ASPECTO (RELACIÓN ENTRE AGENTE Y ACCIÓN)}

Algacel sabe muy bien que la doctrina emanacionista de Avicena tiene dificultades para conciliar el principio que dice «Del uno solamente procede el uno» ${ }^{16}$ con el de la pluralidad del universo creado, y analiza sus explicaciones. Averroes, enseguida llama la atención de su lector para advertirle que el emanacionismo es un desarrollo de «los filósofos tardíos del Islam» (TT 173).

Para los avicenianos, la solución a dicha dificultad consiste en que el mundo plural no emana directamente de Dios, unidad absoluta, sino por una mediación. Algacel pone en boca de ellos el siguiente argumento: toda diferencia en cualquier acción se debe a diferencias en las potencias agentes, en los materiales, o en los instrumentos, o bien a una concatenación de actos, $\mathrm{y}$ «dado que todas estas divisiones son imposibles en el seno del Primer Principio» (TF 66 [37]), los filósofos sostienen que la única forma de que resulte la pluralidad es por mediación, a través de un intermediario. Avicena, en el Shifá ' y en otros libros ${ }^{17}$, habla de este proceso, que empieza con la creación de una primera inteligencia, pero no encuentro el argumento detallado tal como lo expone Algacel. A pesar de ello, el argumento de Algacel es compatible con Avicena.

En su respuesta, Algacel objeta que por la mediación solamente se producen átomos o mónadas, no elementos compuestos, tal como son las sustancias de nuestra experiencia (TF 66 [39]). Está dispuesto a admitir una multiplicidad numérica, pero no cualitativa.

La reacción de Averroes supone un distanciamiento explícito de Avicena. Según él, Alfarabi y Avicena admitían que el agente simple o absoluto en el mundo visible es igual que el agente simple en el mundo invisible (es decir, Dios) y esto es un grave error (TT 175). Averroes distingue entre los procesos del mundo sublunar y la emanación de las inteligencias separadas de la materia. En el mundo libre de materia, del agente absoluto, es decir, de Dios emana una acción muy específica:

Del Agente absoluto solamente emana una acción absoluta, y esta acción no se particulariza en efecto alguno. Por esto Aristóteles demostró que el [entendimiento] agente de los inteligibles humanos es un entendimiento libre de materia, es decir, por su manera de ser hace entender todas las cosas, y de la misma manera demostró que el entendimiento paciente no es generado ni se destruye, porque entiende todas las cosas (TT 180: 7-11).

Con respecto del mundo visible, Averroes no habla de èmanación sino de que la unidad se difunde entre los seres como el calor del fuego entre los cuerpos. Averroes tiene una posición distinta, que asegura es la de Aristóteles, y no comparte las tesis que Algacel atribuye a los filósofos. Estos dividen los seres en aquellos que existen en un sujeto, y los que no existen en un sujeto, etc. (TF 67) para terminar en la exposición del sistema emanacionista (TF 6769), como podemos leerlo en Alfarabi ${ }^{18}$, mejor que en Avicena ${ }^{19}$, basado en mecanismos de intelección. Volveremos enseguida sobre esta cuestión, es decir, cómo se entiende a sí mismo y genera un primer efecto, etc.

16 Citado por ejemplo en Ishârât, pp. 153-154, donde excluye que la dualidad proceda del uno, ya que afecta a los constituyentes, a los concomitantes necesarios o implica una división.

17 Ilâhîyât, VI.9, pp. 390-393. Ishârât, p. 452. Najât, ed. Cairo, p. 448-455, ed. Fakhry, p. 310-314.

18 Ciudad virtuosa, Kitâb ârâ'ahl al-madîna al-fâdŭla, ed. Albert Nâdir, (Beirut, 1996), pp. 55-58. Trad. M. Alonso, (1961-62. Madrid, 1995), c. 7-8, pp. 21-25. Política, Kitâb as-siyâsa al-madanîya, ed. bilingüe Rafael Ramón, en Obras filosoffico-políticas (Madrid, 1992), pp. 20-21 o 24-27.

19 Ilahîyât, IX.4, pp. 402-409, (traducción de G.C. Anawati, La métaphysique, vol. 2, pp. 137-144); Najât, pp. 288, y para el mismo Algacel en su posible fase aviceniana, Maqâsid, Las intenciones de los filósofos, pp. 208209. 
Averroes no está de acuerdo con esta ingeniosa doctrina, «invención de Avicena, Alfarabi y otros», y expone su doctrina, apoyada en aleyas. En un ejercicio de interpretación del texto sagrado, hace encajar frases sobre la omnipotencia divina, por ejemplo en Corán 19 (Maryam): 94, dentro de una cosmología, donde los cuerpos celestes solo tienen razón de ser y existir en función de su actividad al servicio del hombre y ello en un plan divino perfectamente diseñado. Averroes, desde luego, argumenta que la creación de los seres privados de materia, las esferas celestes, es muy distinta de la creación de los seres sublunares (TT 184-194).

Pero merece la pena tener en cuenta las objeciones de Algacel a estos filósofos, que Averroes confiesa no seguir, y que están centradas en la distinción entre existencia necesaria o posible (TF 69-70). Algacel califica de delirantes sus doctrinas, según las cuales de la auto-intelección del Uno emana un primer ente cuya existencia es posible en sí misma; este primer efecto conoce a su causa y se conoce a sí mismo, generando dos entes, a los que se suma un tercero, fruto de su manera de ser un existente posible (TF 69 [46]). Para su crítica elige la tesis de que el primer creado es un ser cuya existencia es posible - y no es necesaria como lo es la del Primer Principio-, y que esta característica es el germen de la pluralidad. Dado que los intelectos emanados carecen de cuerpo material, Avicena explica la pluralidad en el primer efecto como resultado necesario de ser posible por sí mismo y necesario por causa del Prime$\mathrm{ro}^{20}$. Algacel formula cinco objeciones, que podemos resumir así:

$1^{a}$ Para que haya pluralidad los avicenianos dicen que la posibilidad de existencia es distinta de la existencia, pero si se afirma esto, también hay que afirmar que la necesidad de la existencia lo es. Existencia es «algo general» que se divide en necesario y posible por igual, como en cualquier divịsión de un género (TF 70). En consecuencia, en el Primer Principio existe una dualidad.

Avicena habla, sin embargo, de que en el Ser de existencia necesaria no hay composición pues si la necesidad de existencia fuera distinta de su quididad o esencia, esta necesidad de existencia estaría ubicada en algo distinto ${ }^{21}$. Un argumento exactamente igual al de Algacel no aparece.

Averroes señala que el primero en desarrollar la doctrina del existente necesario por sí o posible por sí, pero necesario por otro fue Avicena (TT 197-198) ${ }^{22}$. Acepta su doctrina con matices pero se distancia de la posición atribuida a Avicena en cuanto considera que la necesidad de existencia no es algo añadido a la existencia:

Necesario de existencia no es un algo ( $m a$ 'nà) agregado a la existencia externa del alma, solamente es un estado ( $h \hat{a} l$ ) en el ente de existencia necesaria, nada añade a su esencia (dhât, TT 196: 14-15).

Se trata de una condición negativa, prosigue, en cuanto es un ente cuya existencia no necesita de otro. Sin embargo, acabamos de ver que Avicena rechaza que en la realidad ( $h \_a q \hat{\imath} q a$ ) del ser necesario haya distinción alguna, y menos una distinción entre su existencia y la necesidad de la misma. Los ataques de Algacel son serios, pero Averroes ignora una parte importante de las palabras de Avicena.

Para el ente de existencia posible, Averroes no admite tampoco la división real que suele admitirse en Avicena ${ }^{23}$ y que era utilizada por Algacel en su contra, a pesar de que — cómo bien

20 Kitâb at-Ta'lîqât (Anotaciones), ed. Badawî, p. 101.

21 Shifâ', Ilâhîyât, Libro VIII.4, pp. 345-346. Cf. también An-Najât, pp. 263-264; Ishârât, pp. 144-145. Cf. el citado estudio de A.M. Goichon, La distinction de l'essence et de l'existence d'après Ibn Sînâ (París, 1937), p. 346.

22 Van de Bergh ya señaló en 1924 que el primero en distinguir entre ser necesario por sí mismo y necesario por otro, es Aristóteles, por ejemplo Met. V. 1015b 10. Cf. Die Epitome der Metaphysik des Averroes (1924. Leiden, 1970), pp. 150-152.

23 La distinción es clara en Ishârât, p. 140. Ver Goichon, La distinction, pp. 130-148. 
le recuerda - en otros lugares Algacel sostiene que la posibilidad es algo puramente mental (TT 200). Para Averroes es una distinción de razón y aquella existencia que para ser tal necesita de una causa es simplemente «inexistencia» (TT 199). En lugar de la distinción aviceniana, Averroes hace valer la distinción entre causa y efecto, de modo que la pluralidad tiene su origen en el hecho de que el efecto se compone de causa y efecto, por tanto es menos simple que la causa mientras el Primer Principio es simple en términos absolutos (TT 200-201). Esta norma vale tanto para los seres compuestos de materia y forma como para los cuerpos celestes, en los cuales:

El significado (ma 'nà) de 'causa' y de 'efecto' en estos entes equivale al de pluralidad en potencia, la cual se manifiesta en el efecto, es decir, que de la causa emanan múltiples efectos sin que ellos existan en ésta al mismo tiempo (TT 201).

Realmente, la distinción que Averroes introduce entre los seres causados y el Ser causa única, no es opuesta a la distinción entre seres de existencia posible y un Ser de existencia necesaria por sí mismo, sino una variante desde otro punto de vista.

$2^{\text {a }}$ Si el Primer Principio se comprende a sí mismo y conoce las cosas sin que ello implique pluralidad, tampoco se puede afirmar pluralidad en el primer efecto, cuando este conoce a su Principio y se conoce a sí mismo, y a la inversa, si admitimos pluralidad en el segundo, tenemos que aceptarla en el Primero. (TF 70).

Avicena define el Ser Necesario por sí mismo como intelecto puro ${ }^{24}$. Como tal, por ser libre de materia, se entiende a sí mismo. «El hecho de ser entendido y de entender no conlleva la necesidad de ser una dualidad ni en esencia ni en la consideración ${ }^{25}$. Más adelante, Avicena se plantea la aporía de cómo comprende los seres posibles pues si son parte de su esencia, habrá multiplicidad en Él, y si no, se caerá en las «ideas platónicas». La solución aviceniana, si así lo es, consiste en que «Él entiende su propia esencia [i.e., a sí mismo] como principio de la emanación de todos los inteligibles» ${ }^{26}$. De este modo, cree evitar la multiplicidad que implica el conocimiento de los seres, un conocimiento que será solamente universal, no particular.

Algacel conoce bien la solución aviceniana y se centra en ella para intentar deshacerla: Resultará que el efecto es más noble que la causa, pues la causa solamente se comprende a sí misma, mientras que el efecto no sólo se comprende a sí mismo sino que también comprende a su Principio y los demás efectos (TF 71 [57]).

¿Cómo reacciona Averroes? (TT 207-210) Invoca los diferentes niveles de conocimiento, el de la gente sencilla, el dialéctico de los teólogos, y el de los filósofos, basado en la demostración apodíctica. Un conocimiento obtenido de la última forma puede parecerle al hombre de la calle como un sueño, o el delirio del que habla Algacel.

Los filósofos quieren conocer los seres con la ayuda de sus entendimientos, sin confiar en las palabras de aquel que pretende que las acepten sin aportarles una demostración apodíctica (burhân) y aunque a veces los datos de los sentidos contradigan los de la razón (TT 210: 10-211: 1).

La gente sencilla no puede imaginarse que los cuerpos celestes sean creados de manera distinta a la de los seres sublunares, pero no es así (TT 213). El mundo de las esferas es un mundo de formas separadas de materia, ordenadas jerárquicamente, y formando una unidad. 
El Primero de estos seres no se entiende más que a sí mismo, y gracias a la intelección de su esencia, los entiende todos en el grado más alto de existencia, de jerarquía y de orden (TT 217: 10-12).

Averroes acepta en principio la explicación de Avicena, la limita al mundo de las formas separadas, y se esfuerza en justificar su tesis: el conocimiento que tiene el Primer Principio de sí mismo es causa de los demás seres. Sin embargo, parece darse cuenta de las dificultades y alude a que los argumentos de los filósofos «no son menos convincentes» que los argumentos de los teólogos del Kalâm, mu 'tazilí y ash 'arí (TT 218-226). Es decir, procura mostrar que los argumentos de los segundos presentan más deficiencias que los de los filósofos, pero también defiende la postura de estos. El conocimiento divino no es ni universal ni particular, Dios conoce de una manera distinta, de una manera tal que al conocer su propia esencia conoce los entes «en su grado más noble de existencia» (TT 226).

Averroes sigue, pues, a Avicena, pero con matices porque jel orden de la emanación y el número de esferas es algo no probado! En lo que los filósofos están de acuerdo, y esto es algo probado, es en el principio de emanación y en la fuerza que mantiene unido el universo. La fuerza única es la manifestación de la emanación, y la compara con el color y sus distintos 'grados de existencia' según afecte a la materia, a la facultad de la vista, de la imaginación o de la memoria (TT 228). Del Primer Principio emana con certeza una fuerza que mantiene unidas las partes del mundo y Averroes no aprecia que esto afecte a la unidad divina ${ }^{27}$.

En cuanto a la emanación de las formas separadas Averroes da su propia solución: su existencia consiste en las formas con las que perciben el primer Principio (TT 231). Las formas responden a las finalidades que Dios les otorga (TT 232). Su orden no está basado en el espacio físico, sino «quizá en su actividad» (TT 234).

Poco queda de Avicena en el sistema de Averroes. Coinciden en afirmar que Dios es el principio y la causa de la existencia del universo, pero incluso ahí hay grandes diferencias pues la divinidad, en Avicena, está actúa como el factor inicial en los mecanismos de intelección que generan el universo, mientras en Averroes, es un principio metafísico. Volvamos a donde estábamos, como dice Averroes (TT 234: 4 ) 28 .

$3^{\mathrm{a}}$ Dado que el conocimiento es distinto de lo conocido, la pluralidad deriva ya del conocimiento que tiene el Primero de sí mismo. De acuerdo, y prosigue Algacel: ¿por qué no sumar a los tres entes producidos en el seno del primer efecto un cuarto, el hecho de ser de existencia posible, y luego un quinto, el hecho de ser necesario por otro, e ir multiplicando? (TF 73).

Averroes separa la cuestión del conocimiento que tienen los intelectos, de la relativa a la emanación unos de otros. Esta, precisa, no es propia de los antiguos filósofos, de los griegos, sino de Avicena. Los antiguos filósofos reconocen el principio que del uno solo procede el uno, pero que no se aplica por igual a los agentes que son formas materiales y a los que son formas separadas de la materia. Una forma separada no es compuesta en el sentido de la tradición de Alfarabi y Avicena, sino que no es tan simple como el Primer Principio, la Primera Causa:

27 La reminiscencia estoica es evidente: el pneuma todo lo invade e impregna, cf. los diversos testimonios recogidos por J. Von Arnim, Stoicorum veterum fragmenta, vol. 2, (Stuttgart, 1964), pp. 144-151. Sin embargo la vía de la transmisión es algo por dilucidar, cf. J. Lomba, «El estoicismo y la literatura moral andalusí», en Medievalia (México), 14 (1993).

28 Dejo al margen otra objeción de Algacel (TF 72-73), donde Averroes se distancia de la noción atribuida a Avicena sobre ser de existencia posible. Argumenta Algacel en contra de los filósofos que el Primero no puede conocer a otro para impedir que la pluralidad surja en su seno. Por esta misma regla, tampoco el segundo, el primer efecto, puede conocer a su Principio, de lo contrario habría una dualidad, y necesitaría de otra causa distinta del Primero. Luego los filósofos no pueden explicar la multiplicidad. Averroes responde que el conocimiento que la causa obtiene de su efecto no añade nada a su propia esencia (TT 236), y que la crítica de Algacel es válida solamente para los efectos generados temporalmente, los seres de existencia posible propiamente dichos (TT 236 final). 
La diferencia entre la causa y el efecto - me refiero a las formas separadas- estriba en que la Causa Primera existe por sí misma, mientras la causa segunda existe debido a su relación para con la Causa Primera, porque el hecho de ser causada es su misma sustancia (TT 238: 2-4).

De nuevo recurre a la doctrina de los niveles ontológicos distintos a la causa y al efecto, para insistir en la naturaleza relacional del segundo en el caso de las formas separadas. ¿Qué significa 'relacional' en Averroes? Sin ninguna duda, una forma de existir unida necesariamente a otro ser, a la causa, sin posibilidad de existir independiente y esta forma de existir es propia de los cuerpos celestes que, para él y los medievales, eran sustancias separadas de la materia.

$4^{\mathrm{a}} \mathrm{La}$ triplicidad o trinidad en el primer causado no es suficiente para explicar la multiplicidad (TF 73-76). El primer cuerpo emanado está compuesto en varios sentidos: de materia y forma, tiene una magnitud por adición de algo que la determina, está dividido entre dos polos.

La doctrina diciendo que los cuerpos celestes están compuestos de materia y forma no aparece en Aristóteles, aunque en Avicena se presta a confusión a causa de la llamada forma corpórea $^{29}$. Averroes acusa directamente a Avicena de mal interpretar a Aristóteles y recuerda que el cuerpo de todos los cielos es un cuerpo simple (TT 239).

En segundo lugar, el cuerpo de la última esfera tiene unas dimensiones definidas gracias a una cantidad que le diferencia de otros y que es «algo añadido a la existencia de sí mismo» (TF 73 [65]) pues su tamaño puede ser mayor o menor. En consecuencia, es un ser compuesto. pero Averroes negará que los cuerpos celestes sean más grandes o más pequeños (TT 240).

La tercera vía de ataque son los dos polos del universo: ¿por qué fueron elegidos estos polos? ¿Es que son diferentes de por sí? Si el filósofo contesta que todas las partes son iguales, Algacel le objetará que es lo que hace dos puntos necesarios, y si dice que hay dos polos porque las partes de la última esfera son diferenciadas, no puede explicarle de dónde viene esta diferenciación, puesto que el primer efecto no la contiene (TF 74 [67]).

Averroes opta por distinguir dos sentidos del término 'simple': uno el aplicado a los cuatro elementos simples, porque su composición es muy «elemental», y otro el aplicado a los cuerpos celestes, porque no están compuestos de materia y forma. La simplicidad de los segundos no impide que «tengan partes diferentes» (TT 243). De nuevo se dirige contra Avicena, Alfarabi y contra el propio Algacel —en su obra El lucidario ${ }^{30}$ - por no saber explicar correctamente la doctrina de que del uno solamente procede el uno (TT 245).

Antes de la última objeción, Algacel intercala una reflexión que dice le correspondería hacer a los filósofos: ¿Acaso no ocurrirá que en el primer efecto existe una multiplicidad que nosotros no somos capaces de percibir? Nosotros solamente somos capaces de comprender tres o cuatro distinciones (TF 74 [68]). Si contesta esto, el filósofo está derivando del primer causado una multiplicidad mucho mayor de la supuesta triplicidad, y así Algacel le fuerza a admitir que todos los entes, en su gran número, han emanado del primer causado, y no solamente el alma y el cuerpo de la esfera más remota más el entendimiento de la tercera. Es más, de admitir esto, no es necesaria la Primera Causa porque todas estas diferencias existen sin una causa necesaria (TF 75 [69]).

Estas distinciones interpreta Averroes que son las hechas por Avicena en el seno del primer causado: en cuanto se entiende a sí mismo o en cuanto entiende al Primero se generan na-

29 Avicena considera inseparable esta forma de todo cuerpo: Kitâb an-Najât, pp. 237-239. Shifâ, Ilâhî 'îyât, I.6, p.

Ver también su definición de hayâlî en Rasâ'il mantiqîya fi l-ḥudad wa-r-rusûm, ed. 'Abd al-Amîr al-A'sam (Beirut, 1993), p. 129. Trad. A-M. Goichon, Introduction à Avicenne. Son épître des definitions. París 1933.

30 Mishkât al-anwâr. Ed. bilingüe, trad. David Buchman: The Niche of the Lights. Provo, Utah: Brigham Young University, 1998 
turalezas o formas distintas ${ }^{31}$. Ahí Averroes, que califica de fábulas estas doctrinas, le da la razón a Algacel (TT 245-246) y con acierto objeta que no hay ningún motivo para considerar una de las naturalezas como emanando del Primer Principio, y la otra, no.

Averroes está de acuerdo con esta y otras críticas de Algacel ${ }^{32}$ a los filósofos, sin que podamos, por ahora, averiguar si los razonamientos se encuentran en alguno de ellos, o son obra del propio Algacel. En todo caso, Averroes atribuye de nuevo a Alfarabi y a Avicena la autoría, y propone su solución, que estriba en combinar los principios metafísicos de pluralidad y de unicidad; la pluralidad es intrínseca a lo causado, y la unicidad es una razón emanada de la Unidad:

En el primer causado hay pluralidad necesariamente, y toda pluralidad adquiere unidad a causa de una unicidad trascendental ( $w a h \_d a n \hat{n} y a$ ) superior que hace que se remonte a la Unidad, y esta unicidad, debido a la cual la pluralidad se hace unidad es una razón (ma'nà) simple, emanada de una Unidad separada y simple (TT 249).

Su propuesta no la considera suya propia, sino que la encuentra ya en Aristóteles, en la parte final del libro Lâm de la Metafísica, donde habla de un solo motor eterno, y no de emanación (TT 250).

$5^{\text {a }}$ Haciendo el simulacro de admitir el sistema emanacionista alfarabiano, Algacel propone emplear «un hombre ausente» en lugar de la última esfera, como primer efecto, puesto que «la posibilidad de la existencia es un concepto que no cambia porque cambie su posible objeto, tanto da si es un hombre, un ángel o una esfera» (TF 77 [75]). Sin embargo, si hacemos esto, nadie nos tomará en serio.

Aunque a primera vista nos sorprenda, en su respuesta, Averroes (TT 253-254) reconoce 'cierta' validez a las doctrinas avicenianas, en el supuesto de no hacer una lectura literal de las mismas, sino una lectura figurada (tamthîlîya). «Primer efecto» es un concepto filosófico que puede describirse con ayuda de la imagen de la última esfera, o de un hombre invisible, a un nivel de explicación inferior al filosófico. Con estas limitaciones, las doctrinas de Avicena no son tan erróneas como pretende Algacel:

Estas son las teorías de Avicena y de sus seguidores, que no son ciertas ni están construidas sobre fundamentos filośficos; sin embargo no son tan malas como dice Algacel, ni las presenta tal como son. Aquel hombre que suponemos que tiene una existencia posible por sí misma y necesaria por causa de otro, que se conoce a sí mismo y a su agente, puede ser una representación adecuada de la causa segunda, si suponemos además que a través de su esencia y de su conocimiento es causa de los demás seres, tal como piensan Avicena y su escuela del segundo principio (TT 252: 14-253: 5).

Averroes está de acuerdo, pues, con Avicena de manera limitada. Aún más: antes hemos visto que no compartía la explicación aviceniana sobre el origen de la multiplicidad, porque no consideraba que la división entre esencia y existencia en los entes de existencia posible fuera una división real (supra, TT 199), ahora parece aceptarla sometida a una lectura figurada...

Finalmente, en un gesto frecuente en él, asimila la postura de los filósofos a la de los mutakallimíes y de Algacel, y vuelve a repetir que Algacel solamente estudiaba las obras de Avicena, de ahí sus deficiencias (TT 254). Aunque Algacel haya terminado con la exposición de sus cinco objeciones -y Averroes con su discutible refutación-, resume su posición afirmando dos principios de los filósofos niegan. Niegan estos, según él, que la dualidad proceda

31 Ishârât, pp. 173-174.

32 Verlas en TF 75-76, sobre la posibilidad de que los miles de caracteres distintos procedan directamente del primer efecto, cuya esfera contiene miles de estrellas... 
directamente del Uno, y que el Uno posea atributos eternos, pero ninguna de las dos proposiciones es contraria a la razón, y los filósofos no prueban que no sean posibles, ni mediante la necesidad del entendimiento ni mediante la reflexión. ¿Cómo demuestra Algacel sus tesis? Mediante el recurso a la religión, al mensaje de los profetas, que en última instancia sabemos lo son por los milagros, y renunciando a la comprensión racional de «cómo el acto de Dios emana de su voluntad» (TF 77 [79]).

Averroes acepta que muchos hombres no estén en condiciones de comprenderlo, pero no todos, es decir, los filósofos pueden. No va a entrar en la segunda tesis - los atributos eternosy se limita a la primera - del Uno no puede emanar una pluralidad. La generación de la pluralidad se produce, según él, por tres causas: la materia prima, los instrumentos o los intermediarios utilizados, y puede también producirse por causa de los distintos agentes. La respuesta de Averroes no es detallada y remite, fundamentalmente, a textos aristotélicos tales como Acerca de la generación y la destrucción, Acerca del alma y se sobreentiende, la Metafísica (TT 259-262). La armonización entre un sistema emanacionista, el neoplatónico seguido por Avicena, y otro funcionalista, el aristotélico, tal como Averroes pretende, no es nada fácil.

Estamos ahora en disposición de responder a las preguntas que nos hacíamos al principio, y en primer lugar, si Averroes atribuye correctamente a Avicena sus opiniones. Suele ser así con una excepción notable: cuando pretende que Avicena admite en el seno del ser necesario una distinción entre quididad - necesidad de existencia- y existencia (p. 7). Evidentemente, Averroes rechaza también toda división real en el seno del ser de existencia posible, y aún más, está en contra de la construcción «posible por sí mismo y necesario por causa de otro», porqué entiende que la naturaleza necesaria no puede convertirse en posible y a la inversa. Para él la división primaria es entre causa y efecto, siendo la causa más simple que el segundo, que contiene el germen de la pluralidad, de modo que no acepta la explicación de que la pluralidad nace en cuanto el primer efecto se conoce a sí mismo y conoce su causa.

La crítica fundamental de Averroes procede de su rechazo del sistema emanacionista, del que Avicena es su mejor representante en la filosofía islámica. Averroes solamente acepta una emanación restringida a los cuerpos celestes y definida por las formas (suwar) mediante las cuales aprehenden la Causa Primera ${ }^{33}$. Nos dice que el mecanismo aviceniano debe entenderse de manera figurada, y no acepta la necesidad de unos intermediarios para explicar la creación. Su tesis es que el primer efecto contiene en sí el principio o fundamento de la pluralidad, a la vez que subsiste gracias a la unicidad que emana de la Causa Primera. Frente a la doctrina de unos seres abstractos que conocen al Principio y se conocen a sí mismos, ingeniosa pero superficial, Averroes defiende una concepción realmente filosófica de los principios y de las causas. No se trata de una metafísica del esse, pero sí de la unidad trascendental (wahdânîya) surgida de la Unidad en sí.

Su crítica a Avicena le lleva a coincidir con Algacel en estos casos, pero no en lo esencial: la acción divina en la creación no es asimilable a los actos humanos y los filósofos aciertan en su explicación de Dios como causa eficiente del universo. Averroes está cerca de Avicena y está dispuesto a seguir sus palabras, a condición de hacer una interpretación metafórica.

Josep Puig Montada

Departamento de Estudios Islámicos

Facultad de Filología 28040 Madrid

33 Acertadamente Jean Jolivet utiliza para describir el proceso la expresión de causalidad noética, ver su artículo: «Divergences entre les métaphysiques d'Ibn Rušd et d'Aristote», Arabica 29 (1982), pp. 230-234. B.S. Kogan, a su vez, habla de «causal knowing», en Averroes and the Metaphysics of Causation, Albany, N.Y.: SUNY Press, 1985. 